OPEN ACCESS

Edited by:

Tamás Laskay,

University of Lübeck, Germany

Reviewed by:

Ricardo Silvestre,

University of Minho, Portugal

Nicola Ivan Lorè,

Division of Immunology, Transplantation and Infectious

Diseases, IRCCS San Raffaele

Scientific Institute, Italy

Nathan Peters,

University of Calgary, Canada

*Correspondence:

Thomas T. Murooka

thomas.murooka@umanitoba.ca

Specialty section:

This article was submitted to

Microbial Immunology,

a section of the journal

Frontiers in Immunology

Received: 24 February 2021

Accepted: 07 May 2021

Published: 19 May 2021

Citation:

Zayats R, Uzonna JE and Murooka Tा

(2021) Visualizing the In Vivo Dynamics of Anti-Leishmania Immunity: Discoveries and Challenges.

Front. Immunol. 12:671582.

doi: 10.3389/fimmu.2021.671582

\section{Visualizing the In Vivo Dynamics of Anti-Leishmania Immunity: Discoveries and Challenges}

\author{
Romaniya Zayats ${ }^{1}$, Jude E. Uzonna ${ }^{1,2}$ and Thomas T. Murooka ${ }^{1,2^{*}}$ \\ ${ }^{1}$ Rady Faculty of Health Sciences, Department of Immunology, University of Manitoba, Winnipeg, MB, Canada, \\ ${ }^{2}$ Rady Faculty of Health Sciences, Department of Medical Microbiology and Infectious Diseases, University of \\ Manitoba, Winnipeg, MB, Canada
}

Intravital microscopy, such as 2-photon microscopy, is now a mainstay in immunological research to visually characterize immune cell dynamics during homeostasis and pathogen infections. This approach has been especially beneficial in describing the complex process of host immune responses to parasitic infections in vivo, such as Leishmania. Human-parasite co-evolution has endowed parasites with multiple strategies to subvert host immunity in order to establish chronic infections and ensure human-to-human transmission. While much focus has been placed on viral and bacterial infections, intravital microscopy studies during parasitic infections have been comparatively sparse. In this review, we will discuss how in vivo microscopy has provided important insights into the generation of innate and adaptive immunity in various organs during parasitic infections, with a primary focus on Leishmania. We highlight how microscopybased approaches may be key to providing mechanistic insights into Leishmania persistence in vivo and to devise strategies for better parasite control.

Keywords: two-photon intravital microscopy, Leishmania infection, T cells, ear skin imaging, liver imaging, fluorescent reporters, macrophages

\section{INTRODUCTION}

The immune system must rapidly mobilize immune cells to appropriate tissue sites to eliminate infections, but at the same time, must be tightly regulated to prevent excessive tissue damage. This is largely achieved by the exquisite ability of immune cells to continuously survey most organs in the body, and by coordinating cell-cell communication among different cell types to generate antigen and site-specific immunity. Immune surveillance in vivo is orchestrated by a number of extrinsic factors that are impossible to fully recapitulate in their full complexity outside of the living organism. To address this, time-lapse intravital microscopy (IVM) has been used to capture cell motility and cell-cell interaction dynamics within physiological tissue environments, where stromal cell networks, physiological blood flow, lymphatic drainage and innervation remain intact. More recently, two-photon microscopy (2P-IVM) has emerged as the gold standard for in vivo imaging and represents an important imaging platform to refine and extend observations derived from cell culture studies. While initial studies focused on cellular dynamics at steady-state or using model antigen systems, more recent $2 \mathrm{P}$-IVM studies have focused on visualizing immunity generation in response to natural infections, solid tumors and evaluating candidate vaccine efficacy in vivo. 


\section{TWO-PHOTON INTRAVITAL MICROSCOPY (2P-IVM): THE GOLD STANDARD FOR IN VIVO IMAGING}

Much of our understanding on immunity generation against pathogens have been derived from in vitro imaging studies and static histological analyses that fail to fully capture the biomechanical, physicochemical and immunological aspects of complex tissue environments. Two-photon microscopy is a powerful tool that allows researchers to visually characterize cellular dynamics that dictate the specificity, breadth, and magnitude of immune responses. Pioneering studies using 2PIVM in intact $(1)$ or explanted lymph nodes $(2,3)$ showed that naïve $\mathrm{T}$ cells displayed robust migration in the $\mathrm{T}$ cell zone at speeds higher than those previously reported from in vitro studies (3). Upon contact with antigen presenting cells (APCs) presenting cognate antigen, short-lived interactions were replaced by durable APC:T cell conjugates that lasted for up to 36-48 hours, and these prolonged contacts were crucial for proliferation, differentiation and generation of memory $\mathrm{T}$ cell responses $(1,2)$. Similar interaction dynamics were reported between thymocytes and stromal cells during thymic selection, where varying environmental cues dictated thymocyte motility behaviors, differentiation and function (4). 2P-IVM has also aided in uncovering the $\mathrm{B}$ cell dynamics in the germinal centers, where they were observed to be highly motile around the DC network (5), increasing their chances of encountering specific antigen and receiving necessary survival signals. Interestingly, B cells appear to compete with each other for both the antigen and $\mathrm{T}$ cell help $(5,6)$. More recent studies have incorporated fluorescent reporters to measure signal transduction in living cells, integrating changes in cell migration behaviors with signaling status $(7,8)$. These transformative studies have laid the foundation for in vivo characterizations of immune responses to a wide range of natural infections, where the nature of the pathogen dictates how adaptive immunity is generated (9-13).

The concept of exciting a molecule from the ground state to a higher energy state with two photons with identical frequencies was predicted by Marie Göppert in the 1930s (12). It wasn't until 1990 when Wilhelm Denk developed the first two-photon microscope by combining a point-scanning microscope with an infrared mode-locked laser (14). In contrast to deactivation and emission of a fluorophore following single photon excitation, the near simultaneous absorption of two photons of higher wavelength, or half the energy, only occurs at the focal plane (14) (Figure 1A). This negates the need of a pinhole in front of the detection unit, as only the desired fluorophore is excited at the focal plane (Figure 1B). This results in significantly reduced photobleaching and phototoxicity of out-of-focus specimens and
A

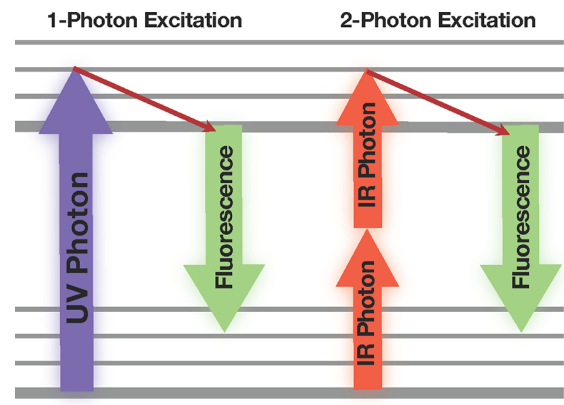

1-Photon Excitation

B

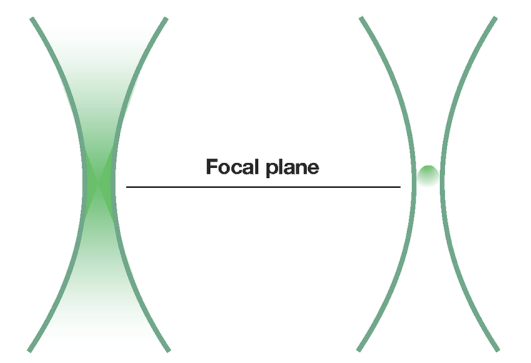

C

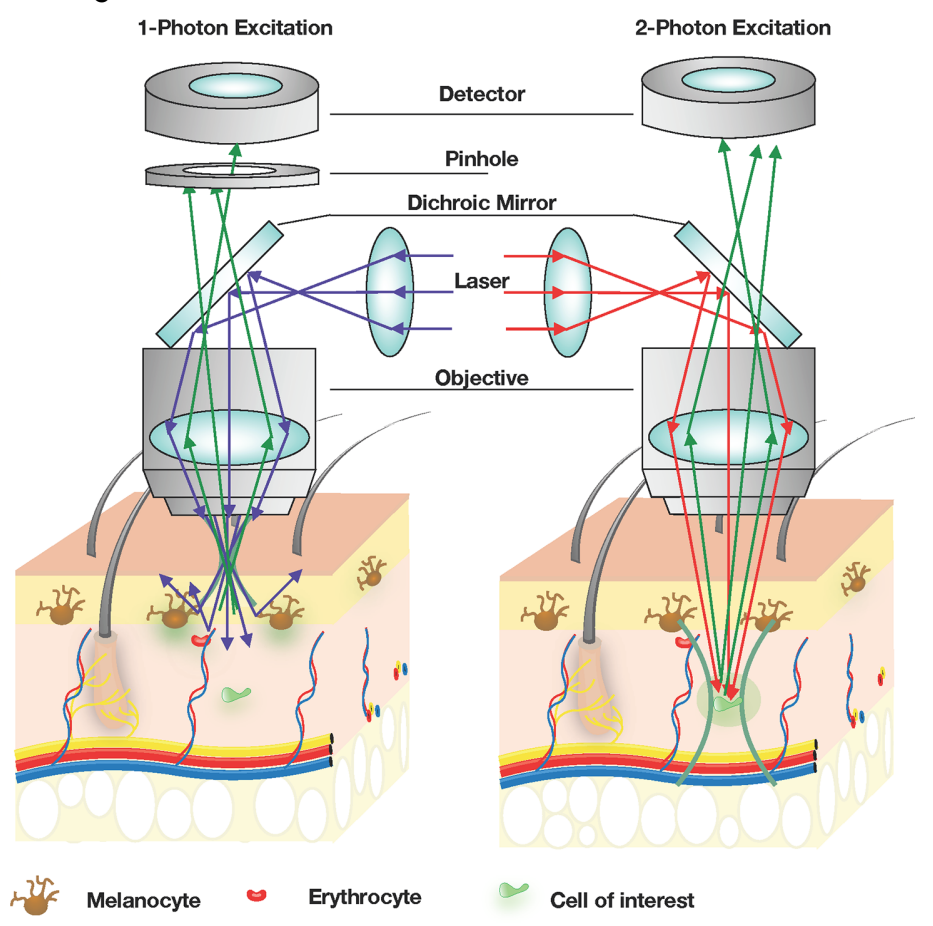

FIGURE 1 | 2P-microscopy is the gold standard for intravital imaging. (A) Jablonski diagram, illustrating the principles of excitation with one Ultraviolet (UV) photon and two Infrared (IR) photons. (B) Spatial confinement of signal generation. 1-photon excitation generates visible (green) signal in the entire cone of fluorescence, while 2-photon excitation generates a signal only at the focal spot. (C) 1-photon excitation microscopy of the skin leads to a low light penetration, which becomes scattered by melanocytes and erythrocytes, while 2-photon excitation leads to a deeper penetration will less light scattering. 
allows for 3D imaging for longer durations compared to conventional single-photon lasers (Figure 1C). Additionally, long wavelength near-infrared light permits deeper penetration into tissues with minimal light scattering and lower bystander absorption from water and pigment-containing proteins, such as melanocytes and heme molecules in erythrocytes $(15,16)$. When combined with fluorescent proteins/dyes that emit across the entire visible spectrum, availability of various fluorescent reporter mouse models and improvements in 4D analysis software capabilities, 2P-IVM approaches are becoming increasingly accessible to more research labs and applicable for a wide range of research areas.

Over the last two decades, 2P-IVM studies have helped characterize the spatiotemporal dynamics of immune responses to viral, bacterial and parasitic infections, and uncovered unique in vivo behaviors such as pathogen dissemination by phagocytes $(17,18)$, swarming responses by neutrophils to injurious insults (19-21), and bacterial reservoirs following infection (22). More recently, immune homeostasis functions of tissue-resident macrophages have been brought to light, such as their ability to rapidly sequester dead cells in the liver (23) and phagocytose inhaled bacteria in the lungs (24) in order to shield them from neutrophils and prevent further recruitment and tissue inflammation. While much focus has been placed on viral and bacterial infections, 2P-IVM studies on parasitic infections in vivo have been comparatively sparse. In this review, we will discuss how the utility of 2P-IVM approaches, and how this imaging modality has advanced our understanding of antiparasitic responses in vivo, with a focus on adaptive immunity against the parasite Leishmania.

\section{VISUALIZING ANTI-PARASITIC IMMUNITY GENERATION IN VIVO}

Despite numerous animal models that are available to study the pathophysiology of parasitic infections, this field remains vastly understudied in vivo compared to viral and bacterial infections. The threat of eukaryotic parasites continually expands into nonendemic countries with the rising climate temperatures, and diseases caused by these pathogens are a great threat to both human and other mammalian hosts, many of which have no cures or vaccines available. Vaccine development against parasitic infections have been hampered due to the complexity of the parasitic life cycle. For example, Plasmodium spp. undergo sexual and asexual stages and alternate between the human and mosquito hosts. While the live attenuated vaccine did provide protection against wild-type Plasmodium falciparum challenge, RTS,S, a recombinant protein vaccine, which is the only FDAapproved vaccine against a human parasitic disease of any kind to date, only has $26-50 \%$ efficacy and only provides short-term protection (25). Parasites have and continue to evolve with their hosts. Their sustained success is due to their remarkable ability to avoid detection and clearance by the host immune system. Antigenic variation, which includes continuous recombination with silent genes and epigenetic switching of sub-telomeric genes is one of the common immune evasion strategies (26). Another strategy is to encode a large number of genes that actively promote immune evasion. Plasmodium relies on immune dysregulation to avoid clearance, such as activation of B cells independently of T cell help by crosslinking B cell receptors with repetitive epitopes present on the circumsporozoite protein; immunosuppression through engagement of CD36 and CD51 on DCs in order to impair maturation and subsequent $\mathrm{T}$ cell priming; and activating immune checkpoint molecules on CD4 and CD8 T cells (27). These immunosuppressive mechanisms prevent establishment of long-term memory responses and help promote a state of persistent infection.

Leishmaniasis, a disease caused by the Leishmania spp., varies in severity depending on the species of Leishmania and the type of immune response mounted by the infected individual. Based on the parasite species, organs infected, and symptoms produced, leishmaniasis presents in three different forms: mucocutaneous, cutaneous (CL), and visceral (VL), also known as kala-azar (28) (Table 1). The severity of disease progression is dictated by a number of factors, including the infecting parasite dose $(29,30)$, composition of sand fly saliva (31), site of infection (32), degree of tissue damage (17), host skin microbiome $(33,34)$ and the sand fly gut microbiota (35-37). The most important parameter that dictates disease severity is the type of immune response developed by the host. Because Leishmania are obligate intracellular parasites and not neutralized by antibodies, patients with a predominantly humoral response are unable to control parasite load and exhibit a severe form of the disease, called diffuse cutaneous leishmaniasis $(38,39)$. Individuals who develop a strong $\mathrm{CD}^{+} \mathrm{T}$ cell response, characterized by high IFN $\gamma$ production and strong delayed-type hypersensitivity reactions, are able to better control the infection, where intracellular parasites are cleared by nitric oxide produced by IFN $\gamma$ activated (40-42) cells of the mononuclear phagocyte system (42-46). However, an exaggerated T cell response can also lead to immunopathology which, in severe cases, can lead to mucosal leishmaniasis (47). Patients that heal their primary infections develop immunity against secondary infections but this requires the presence of a small number of persistent parasites in the lesion that remain there indefinitely $(38,48-53)$. Persistent parasites have been detected in three-year old skin lesions (54) as well as in extralesional sites $(55,56)$, and can contribute to a late cutaneous manifestation of visceral leishmaniasis, termed post-kala-azar dermal leishmaniasis (PKDL) $(57,58)$ in humans. Numerous factors allowing the parasites to persist have been speculated (59), and these observations indicate that while the presence of live parasites may generate immunity against reinfections, there is inherent risk for disease reactivation, especially in immunocompromised individuals $(60,61)$. This has been demonstrated in mice, where the expansion of Treg cells in vivo causes reactivation of disease in tissues at the site of primary skin infection long after it has healed (62), while depleting Tregs during the secondary challenge prevents disease reactivation at the site of infection and enhances early parasite clearance $(63,64)$. Thus, some of the greatest challenges in developing a vaccine against a vector-borne infection, such as 
TABLE 1 | Human manifestation of leishmaniasis caused by Leishmania spp.

\begin{tabular}{llll}
\hline Geographical location $\quad$ Subgenus & Species & Manifestation
\end{tabular}

\begin{tabular}{|c|c|c|c|}
\hline $\begin{array}{l}\text { Old world Eastern } \\
\text { Hemisphere: Asia, Africa, } \\
\text { and South Europe }\end{array}$ & L. (Leishmania) & L. major & CL, ML (rare) \\
\hline
\end{tabular}

L. tropica CL, ML (rare), VL (rare)

L. aethiopica $\quad \mathrm{CL}, \mathrm{DCL}$

L. infantum, L. chagasi

L. donovani

CL, VL, PKLD, ML (rare)

$\mathrm{CL}, \mathrm{ML}$ (rare), VL (children), PKLD

\section{New world Western}

Hemisphere:

From Southcentral Texas

to South America,

excluding Chile and

Uruguay.

\section{L. (Leishmania) L. infantum}

L. mexicana, $L$.

amazonensis

L. Niannia)

\section{L. braziliensis, $L$.} guyanensis, L. panamensis
CL, ML (rare), VL (children), PKLD (rare)

CL, DCL (rare)

CL, DCL, ML

L. peruviana

CL

Painless, often severely inflamed, ulcerated lesions. Heal within 2-8 months. Often present with multiple lesions which could become secondarily infected. These lesions are slow to heal and may leave disfiguring scars.

Painless multiple dry ulcers in the skin. Heal spontaneously within a year, often leaving disfiguring scars. May lead to Leishmaniasis recidivans, a chronic form of cutaneous leishmaniasis, presenting with slowly progressing lesions which, if left untreated, become destructive and disfiguring. Cutaneous nodular lesions, occasionally oronasal lesions, which distort the nostrils and lips. Progress slowly and may spread locally, taking 2-5 years to heal. Late or absent ulceration. Parasites can cause diffuse cutaneous leishmaniasis, characterized by widely disseminated nodules, most commonly on the limbs and skin. Leads to thickening of the eyebrows and resembles lupus. Does not heal and relapses frequently.

Single nodular lesions with little inflammation, ulcers. Lesions heal spontaneously in a year. Splenomegaly +/- hepatomegaly, pallor of mucosal membranes. Signs of malnutrition as disease progresses. Rare complications include severe acute haemolytic anaemia, mucosal hemorrhage, and acute renal damage.

Splenomegaly $+/$ - hepatomegaly, pallor of mucosal membranes. Signs of malnutrition as disease progresses. Rare complications include severe acute haemolytic anaemia, mucosal hemorrhage, and acute renal damage. Post-kala-azar presents with hypopigmented or erythematous macules anywhere on the body, which become popular or nodular. Buccal and genital mucosa, and the conjunctiva may become affected.

Clinically similar to old world $L$. infantum infection. Most cases occur in children under ten years of age. Some patients develop clinical visceral leishmaniasis. CL in the New World is often atypical.

Cutaneous lesion occurring anywhere on the body post bite, which ulcerates and expands and heals spontaneously within 34 months. Diffuse cutaneous leishmaniasis is similar to Old World manifestations and does not heal spontaneously. Cutaneous lesions occurring anywhere on the body post bite, which ulcerates and expands. May involve the lymphatic system, leading to lymphadenopathy. May heal on its own after 6 months.

Disseminated cutaneous leishmaniasis may occur, with over 20 and up to hundreds nodular or ulcerated lesions occurring without the involvement of the mucosa. Mucocutaneous manifestation can present from several months to 20 or more years after a cutaneous lesion. Nasal lesions are always present, leading to obstruction of the nostril, perforation of the septum, and eventual collapse. One third of the patients have the pharynx, palate, larynx, trachea and upper lip affected. ML almost never heals spontaneously. Secondary bacterial infections are common.

Lesion occurring anywhere on the body post bite, which ulcerates and expands. May involve the lymphatic system, leading to lymphadenopathy. May heal on its own after 6 months.

\footnotetext{
CL, Cutaneous Leishmaniasis; ML, Mucocutaneous Leishmaniasis; VL, Visceral Leishmaniasis; DCL, Disseminated Cutaneous Leishmaniasis; PKLD, Post-Kala-Azar Dermal Leishmaniasis.
}

Leishmania spp., include an incomplete understanding of complex interplay between the parasite, the host immune response and composition of the host/vector microbiome that coordinate the generation of anti-parasitic immunity.
Leishmania parasites undergo a digenetic life-cycle, alternating between residing in a phlebotomine sand fly vector and a mammalian host (65). During an acquisition of a blood meal, an infected sand fly probes the skin and induces bleeding, 
regurgitating the infective metacyclic promastigote form of the parasite into the skin of the mammalian hosts, such as rodents, dogs, and humans $(66,67)$. The flagellated motile promastigotes are then subsequently engulfed by phagocytic cells in the skin. Neutrophils are the first cells to respond to the infection, but inflammatory monocytes and tissue macrophages are the preferred host populations, as described in detail below. Following phagocytosis, it is within the phagolysosome where the parasites transform into the non-flagellated amastigote (38). Once the sand flies ingest infected cells while acquiring another blood meal, the life cycle of the parasite completes inside the gut of the fly.

\section{VISUALIZING LEISHMANIA INFECTION OF THE LIVER}

In order to complete their lifecycle, Leishmania parasites replicate rapidly in the mammalian host to facilitate transmission back into the insect vector. L. donovani, L. infantum, and L. chagasi, which all cause visceral leishmaniasis, can disseminate into the liver, spleen, and bone marrow and cause significant pathology in these organs. The liver is accessible by IVM, as extensive surgery is not required to expose the organ for imaging. For most short-term imaging studies, the liver of anesthetized mice is accessed through a small incision in the abdomen, turning the mouse on its side, gently letting the organ roll out with cotton swabs onto a silicone bed, and placing a custom metal cover slide on top (68) (Figure 2A). For long-term studies, an abdominal viewing window made from a titanium ring and a coverslip (69) is surgically implanted into the mouse abdomen (Figure 2B). In both cases, it is imperative to avoid inducing tissue damage while stabilizing the liver to remove breathing artifacts during intravital imaging.

Granuloma formation is the hallmark of leishmaniasis response in the liver and it consists of mononuclear cells surrounding the infection sites and limiting the spread of parasites. It has been long speculated that liver granulomas form around Kupffer cells, the dominant phagocytic population in the liver, but extensive in vitro studies were not able to confirm their role in antigen presentation within granulomas. Using 2PM-IVM, Beattie et al. showed that Kupffer cells infected with $L$. donovani in vivo engaged in long-lasting interactions with antigen-specific $\mathrm{CD}^{+} \mathrm{T}$ cells, and they were a key player in driving hepatic immunity to infection (70). They visualized, for the first time, motile Kupffer cells migrating from the sinusoids to form almost the entire core of the infected granuloma. They also showed Kupffer cell participation in antigen-specific $\mathrm{T}$ cell activation, localized only to the granuloma site itself (Figure 2C). Using hCD2.GFP reporter mice, they visualized the entire $\mathrm{T}$ cell and NK cell repertoire of the granuloma and found $\mathrm{T}$ cells accumulating around the Kupffer cells from 14 days post-infection. Together they formed granulomas which were smaller and more frequent during the early time points, and larger at 25 days post-infection. The exit rate of cells from the granuloma was influenced by the presence or absence of cognate antigen, but not the entrance rate, indicating antigen-specific retention of the cells since antigenspecific $\mathrm{T}$ cells migrated at lower velocities. These studies provided important insights into the dynamics of liver granuloma function, and the behavior of $\mathrm{CD}^{+} \mathrm{T}$ cells responses within these infection sites. Additionally, the same group characterized the dynamic behaviors of infected vs noninfected Kupffer using TdTomato L. donovani and 2P-IVM to visually identify active infection of the cells (71). Interestingly, inoculation with live parasite amastigotes led to a significant decrease in membrane fluctuation in both infected and uninfected cells, indicating that these changes are not a direct response to intracellular infection itself, but rather due to signals derived from inflammation and bystander activation. These findings corroborate the importance of the local inflammatory milieu that are not adequately recapitulated in in vitro studies of host-pathogen interactions.

$\mathrm{B}$ cell responses are considered to play a minor role in antiLeishmania immunity and have been mostly studied in the context of cutaneous leishmaniasis in vivo $(72,73)$. However, in visceral leishmaniasis, Moore et al. demonstrated that highly motile B cells are present in L. donovani granulomas in the liver, irrespective of their antigen specificity or their capacity to interact with the intra-granuloma T cells (74). However, B cells from naïve and infected mice displayed similar levels of CCR6 in granulomas within 12 hours of adoptive transfer, suggesting that $\mathrm{B}$ cells passively enter the granulomas. It is unclear whether B cells are retained within the granulomas or eventually re-enter the circulation, but using an approach to measure red blood cell velocity in hepatic vessels may help address this question (68). A more recent study demonstrated that $L$. donovani can directly activate B cells via endosomal TLR stimulation, proposing a novel parasite-driven survival mechanism by inducing hypergammaglobulinemia and increased levels of type I interferons, both associated with immune suppression and disease pathology (75) (Figure 2D). This study highlights the potential role $\mathrm{B}$ cells play in exacerbating disease, but this is still controversial, as both pathogenic and protective roles of B cells to other forms of Leishmaniasis have been described (72). Antibodies and serum are not protective against leishmaniasis $(73,76)$, and when donor $\mathrm{CD}^{+} \mathrm{T}$ cells are transferred into irradiated $\mathrm{Balb} / \mathrm{c}$ mice lacking $\mathrm{B}$ cells, they become resistant to Leishmania tropica infection (77). However, IgG-mediated opsonization of $L$. major was shown to promote antigen uptake by DCs, resulting in an increased Th1 response (78) (Figure 2D). Collectively, while B cells are present at the site of Leishmania infection in the liver, their exact role in anti-parasitic immunity or disease progression remains elusive.

While Leishmania donovani infection is generally associated with severe liver and spleen pathology, live parasites have also been detected in the brain (79). Here, using a combination of bioluminescent $L$. donovani and RT-qPCR, Melo et al. detected live parasites in the brain as early as three days post-infection, accompanied by a dual-phase inflammatory response (79). The use of 3D micro-CT was able to pinpoint parasites in the cranial cavity during this early phase of inflammation, which was characterized by CXCL10/CXCR3 and CCL7/CCR2 upregulation and recruitment of 
A
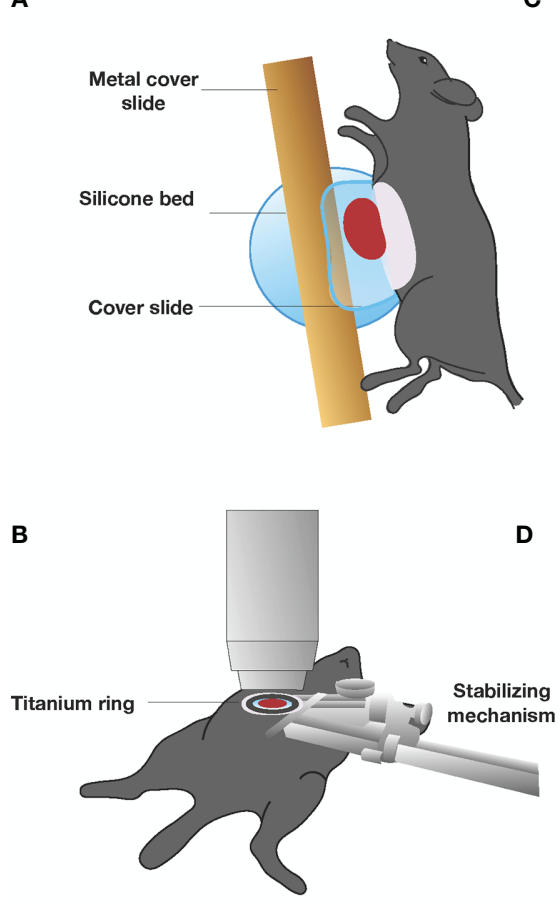
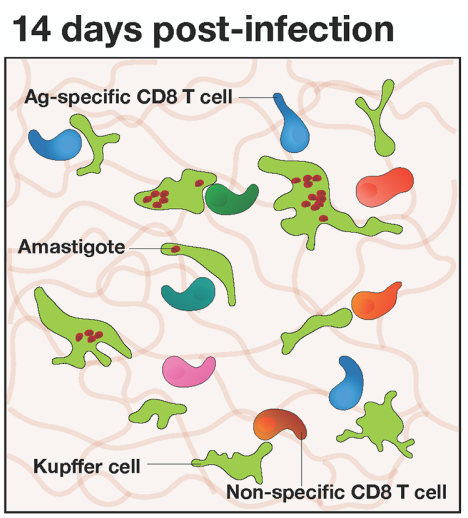

25 days post-infection

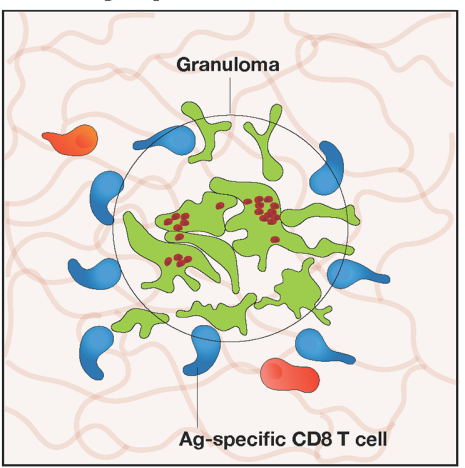

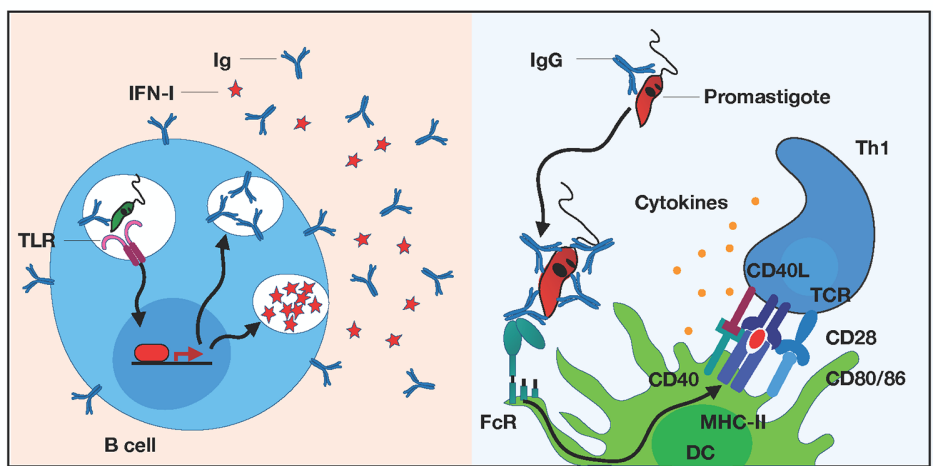

FIGURE 2 | In vivo microscopy of the liver in Leishmania-infected mice (A) Graphical illustration of a mouse preparation for short-term liver imaging. Liver is externalized, placed onto the silicone bed, and covered with a custom metal cover slide. (B) Graphical illustration of a mouse preparation for long-term liver imaging. A titanium ring is surgically inserted into the mouse abdomen and connected to a custom stabilizing mechanism. (C) Granuloma formation in the liver at 14 vs 25 days post infection with Leishmania donovani. CD8 ${ }^{+} \mathrm{T}$ cells are recruited to the granuloma irrespective of antigen specificity, but antigen specific CD $8^{+} \mathrm{T}$ cells are retained at 25 days. (D) Pathogenic and protective roles of B cells in Leishmania immunity. Leishmania donovani can trigger endosomal TLR stimulation, induce hypergammaglobulinemia and increase type I interferons (IFN-I) expression (left panel). IgGs from B cells facilitate opsonization of Leishmania major parasites by DCs via Fc receptors to drive effector Th1 activation (right panel).

neutrophils and Ly6C $\mathrm{C}^{\text {high }}$ monocytes. Collectively, these studies provide evidence that $L$. donovani can infect and inflame the brain and highlight the utility of 2D-3D bioluminescence approaches to detect parasite infections at peripheral sites in vivo.

\section{VISUALIZING IMMUNITY TO CUTANEOUS LEISHMANIASIS IN THE SKIN DURING ACUTE RESPONSES}

\section{Cellular dynamics of innate immunity generation to Leishmania infection}

The ability of Leishmania to access host phagocytic cells to establish a chronic infection is central to their intracellular lifestyle. The first in vivo characterization of the sequence of events after Leishmania major infection was demonstrated by Peters et al., where parasites were rapidly engulfed by swarming neutrophils moments after bites from an infected sand fly in the ear (17) (Figure 3). As neutrophil recruitment and subsequent plug formation was observed in the absence of parasites, this initial response was speculated to occur as a result of the skin piercing damage and not the presence of the parasites themselves $(17,80)$, although TLR2 triggering on non-hematopoietic cells has also been shown to increase recruitment (81). Phagocytosed parasites survive within neutrophils by modulating their ability to kill intracellular parasites, such as hinder their ability to produce reactive oxygen species (ROS) and thus represents a safe haven niche for L. major replication (82). It is important to note that neutrophils can have a protective role, depending on the infection. Neutrophils are protective against L. amazonensis infection which are highly susceptible to histone-dependent killing (83-85). L. braziliensis parasite load was increased after neutrophil depletion in Balb/c mice (86) and amastigotes are killed by neutrophils in vitro (87), indicating that neutrophils are protective in this infection.

Initial studies showed that L. major-infected neutrophils increase CCL3 production (88) which help guide dermal DCs to the site of infection to aid with clearance of infected apoptotic bodies (89). 2PTM studies revealed that CD11c-YFP ${ }^{+}$dermal DCs transitioned from an actively crawling phenotype at steady-state to arrest during L. major infection, accompanied by rapid capture of parasites using 


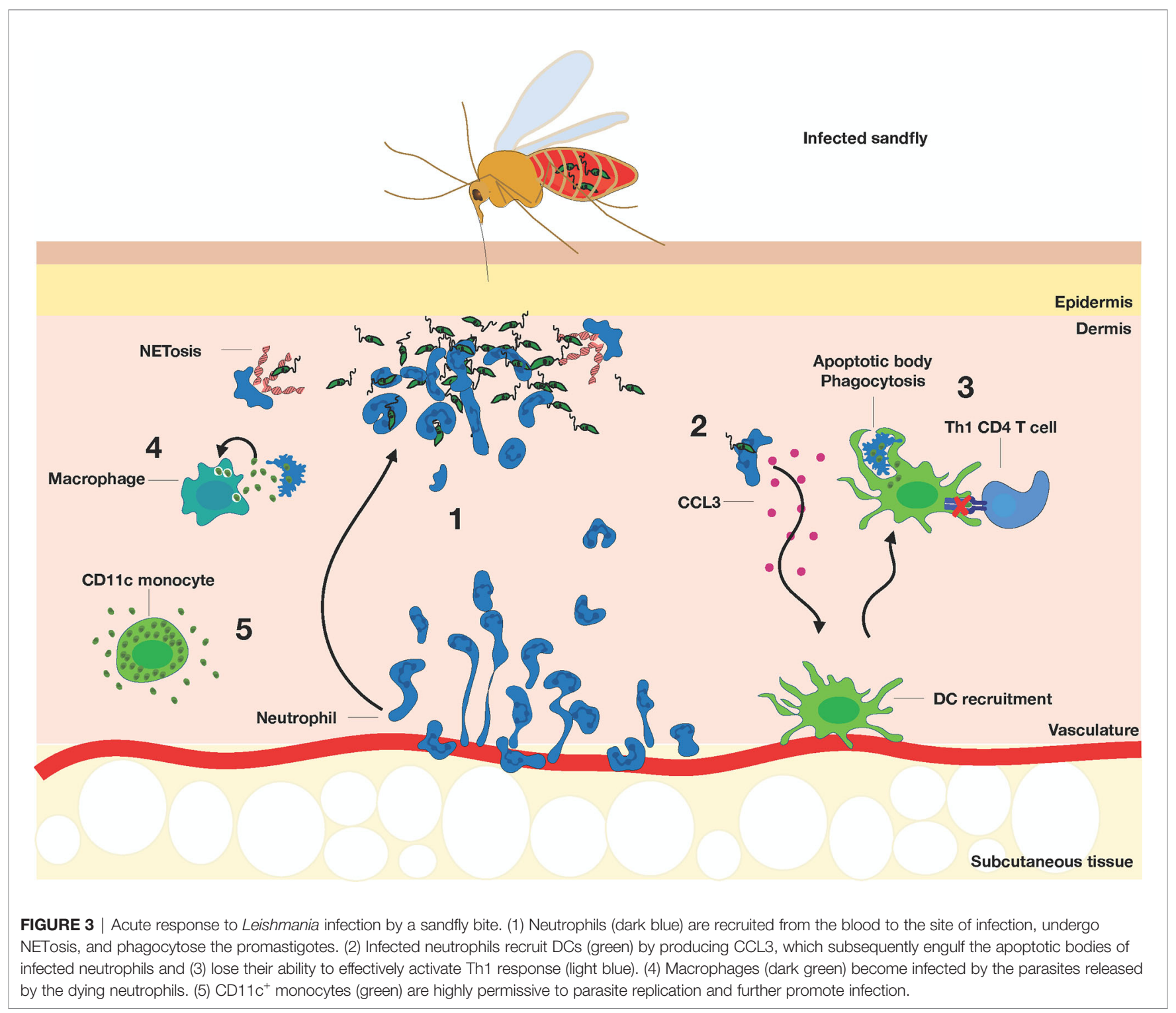

long, motile pseudopods (90). More recent studies have collectively shown that monocyte-derived phagocytes are rapidly recruited and make up the majority of Leishmania infected cells within the first few days $(36,43,45,91)$. A large influx of inflammatory $\mathrm{CD}_{11 \mathrm{~b}}{ }^{+} \mathrm{Ly}_{6 \mathrm{C}}{ }^{\mathrm{hi}} \mathrm{CX}_{3} \mathrm{CR} 1^{+}$monocytes into the primary infection site are observed and make up a large fraction of infected cells by day 2 post-infection, whereas these populations mediate efficient containment during secondary infections (45). Similarly, monocytederived dendritic cell differentiate in the infected skin upon recruitment and drive the generation of protective Th1 immunity against L. major (44). Interestingly, Hurrell et al. showed that infection with Leishmania mexicana induced rapid neutrophil influx and NET release that sequestered but did not impair parasite survival. Instead, the presence of neutrophils impaired early recruitment of monocytes and dendritic cells, delaying adaptive immunity generation through reduced CCL2, CCL3 and CCL5 expression (92). Poor recruitment of monocytes and DCs in vivo $(93,94)$, coupled with low expansion of responding Th1 cells is associated with progressive, non-healing lesion (95-98). These studies support the idea that Leishmania can manipulate host innate responses to facilitate recruitment of susceptible cells, even though some of these cells have leishmanicidal activity (45). Taking advantage of the fact that $L$. major parasites divide once every 15 60 hours inside host cells (99-101), Heyde et al. used a pathogenencoded biosensor to describe a monocyte-derived dendritic celllike phagocyte subset which were highly permissive to L. major replication during acute infection (102). This biosensor system is based on the photoconvertible protein mKikume, which displays green fluorescence in their native form and photoconvert to red fluorescence after excitation with $405 \mathrm{~nm}$ light (103). Because recently divided parasites are green, this allowed researchers to monitor parasite proliferation rates by calculating the green/red color ratio. Intravital microscopy of the ears at three weeks postinfection revealed clusters of highly proliferating parasites that were 
distinct from clusters of low-proliferating parasites, indicating that different cellular niches dictated parasite proliferation and persistence. Imaging studies revealed that parasite proliferation rates vary depending on the phagocyte host, where Ly6C ${ }^{+} \mathrm{CCR} 2^{+}$ CD11c-expressing monocytes were the main reservoir for the most rapidly-proliferating parasites during acute infection (102). While viable $L$. major parasites can be seen released by apoptotic neutrophils in the vicinity of surrounding macrophages (17), direct cell-to-cell transmission was also captured by IVM imaging. Using the non-healing L. major Ryan strain, infected neutrophils can transmit infection to dermal tissue resident macrophages via efferocytosis, or phagocytosis of apoptotic cells, in the first 24 hours of infection (104). In these studies, dermal tissue resident macrophages were initially infected after sand fly transmitted infection, while infection transitioned to myeloid cells including inflammatory monocytes and monocyte-derived dendritic cells by day 12 post-infection. While differences in the parasite dissemination kinetics and target cells involved can be attributed to differences in the Leishmania strain used, infection route and parasite dose, these studies collectively illustrate the various strategies Leishmania employs to hijack physiological phagocytic responses and cell-cell communicative behaviors to access, replicate and disseminate infection to various phagocytic cell subsets in vivo.

Leishmania can circumvent anti-parasitic strategies of phagocytic cells, thereby creating a suitable cellular niche for long-term survival that is shielded from the immune response. Leishmania survives within phagolysosomal vesicles and depend on Th1 cells for cellular activation and parasite clearance (38, 105, 106) (Figure 4). Studies have shown that transition of intracellular parasites from the promastigote to the amastigote stage can upregulate Th2-associated cytokine production within macrophages and promote parasite survival and replication (107). Cytokines IL-4 and IL-13 can also drive an alternative activation of macrophages that promote Th2 effector responses and enhance parasite proliferation and survival $(39,108)$. Additionally, L. major persists in macrophages by expressing pathogenicity factors, such as lipophosphoglycan (LPG), that modify the phagosome into a parasitophorous vacuole (107). These modifications impair vacuole acidification and induce actin accumulation, creating a physical protective barrier around the vacuoles $(107,109)$. Moreover, GP63, a Leishmania protease, has been shown in vitro to affect intracellular signaling and transcriptional activities, leading to a decrease in TNF, IL-12, and NO secretion (110-112), thereby rendering the natural macrophage response insufficient to eliminate parasites. Contrary to these findings, however, in vivo GP63 has been shown to increase TNF and IL-6 production, while enhancing neutrophil and inflammatory monocyte influx to promote infectious spread $(107,113)$. These studies indicate that GP63 may impose varying effects depending on the cell type, and that the tissue microenvironments further dictate function to promote survival. More recently, the L. major Seidman stain, which causes non-healing lesions in C57BL/6 mice (114), was shown to preferentially infect mannose-receptor high M2-like dermal macrophages, which were locally maintained by IL- 4 and IL-10 and were permissive to parasite growth (115). Remarkably, eosinophils were implicated in maintaining the M2-like phenotype of the tissue-resident macrophages (TRMs) through the production of IL-4 (116). In turn, IL-4 and IL-10-stimulated TRMs released CCL24, further recruiting eosinophils and reinforcing the amplification loop. The rapid recruitment of eosinophils and their close interaction with TRMs at both steady state and during infection was elegantly demonstrated by intravital microscopy using eoCre $i l 4 / 13 \mathrm{f} / \mathrm{f}$ mice, where IL-4 and IL-13 deficiency was selectively crossed under the endogenous eosinophil peroxidase promoter. As IL-10 was also required for CCL24 secretion by TRMs, it would be interesting to determine the source of this immunomodulatory cytokine, such as regulatory $\mathrm{T}$ cells.

\section{TH1 CD4 ${ }^{+}$T CELLS ARE INDISPENSABLE FOR LEISHMANIA PARASITE CONTROL}

Th1 cells are responsible for the classical activation of macrophages, being the main source of IFN $\gamma$ aside from Natural Killer cells (108). Th1 cells help infected macrophages clear L. major through the release of both IFN $\gamma$ and TNF, which promote ROS and nitric oxide (NO) production to aid in killing intracellular parasites (117). Activated T cells also upregulate CD40L, which bind CD40 on macrophages and act as a secondary activation signal (118). To counteract $\mathrm{T}$ cell recognition, $L$. major utilizes several mechanisms that interfere with the antigen presentation machinery within infected macrophages (119-122). GP63 can cleave the CD4 molecule on $\mathrm{T}$ cells and suppress MHC-I presentation, physically disrupting $\mathrm{CD}^{+}$and $\mathrm{CD}^{+} \mathrm{T}$ cell activation, respectively (123). Leishmania antigens are sequestered from the MHC-II pathway (124) through fusion of the parasitophorous vacuole with the endocytic organelles to limit access to the antigen presentation machinery. This mode of immune evasion seems to be particularly important during the later stages of infection $(120,121)$. Similarly, infected macrophages activated the Leishmania homologue of receptors for activated $\mathrm{C}$ kinase (LACK)-specific $\mathrm{CD}^{+} \mathrm{T}$ cells at 6 hours post-infection, whereas $\mathrm{T}$ cell activation was drastically reduced at 24 hours and completely abolished at 48 hours post-infection (121), suggesting active suppression of MHC class II pathway. LACK genes are essential for parasite viability and share homologies with mammalian RACK (Receptors for Activated C Kinase) (125). They belong to the WD repeat protein family, playing a role in signal transduction, RNA processing, and cell cycle control and are essential for parasite survival (125). Subsequent reduction in TCR signaling and impaired reorientation of microtubule-organizing center (MTOC) towards the site of contact (120) helps explain poor $\mathrm{T}$ cell responses, but reduction in LACK expression at later timepoints cannot be ruled out, as macrophages infected with amastigotes were unable to stimulate LACK-specific T cells despite addition of stimulatory cytokines (121). Leishmania has also been shown to disrupt lipid rafts that are enriched in peptide/MHC-II complex, thereby decreasing TCR activation threshold $(119,120)$. 


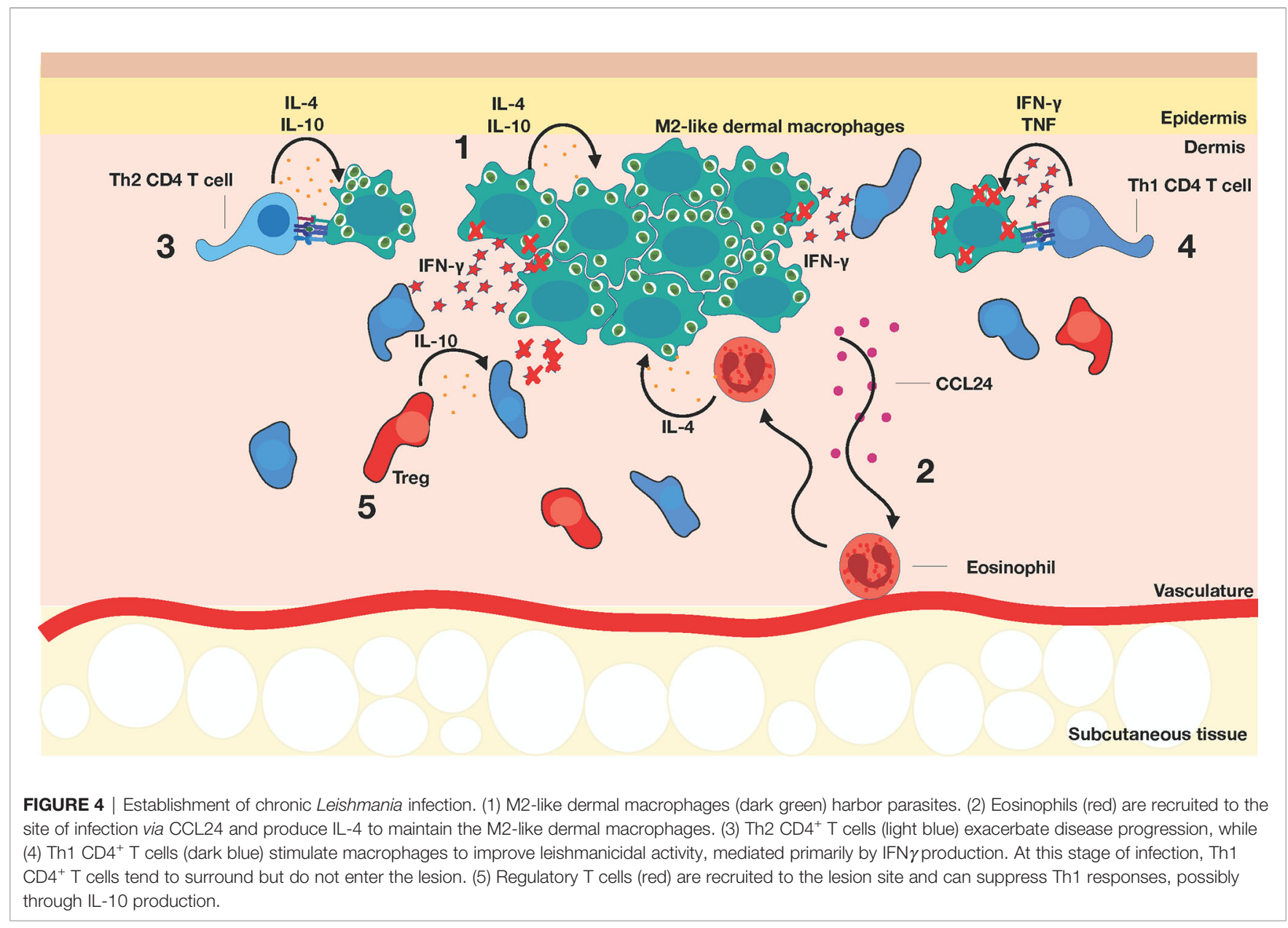

But how do these data translate to the anti-Leishmania $\mathrm{T}$ cell responses in vivo? 2PTM studies visualized, for the first time, that while Leishmania-specific and non-specific $\mathrm{CD}^{+} \mathrm{T}$ cells both homed into infected skin of mice, Leishmania-specific $\mathrm{T}$ cells displayed reduced cell migration speeds and accumulated at the site of infection (126), based on their confined motility behaviors. Interestingly, only a subset of $\mathrm{T}$ cells formed stable contacts with infected cells (126), suggestive of either physical or immunological barriers that resulted in incomplete effector responses. This was not due to the background strain of mice used $[\mathrm{Balb} / \mathrm{c}$, producing a predominantly Th2 response to Leishmania infection (127)] because similar $\mathrm{T}$ cell behaviors were observed with Leishmania-specific $\mathrm{T}$ cells isolated from Th1-dominant C57Bl/6 mice. Studies by Muller et al. showed that paracrine expression of IFN $\gamma$ by T cells can activate infected macrophages up to 80 microns away from the site of macrophage:T cell interactions (128). These studies argue that while L. major employs multiple mechanisms to suppress effector $\mathrm{T}$ cell responses, parasite control can be achieved with activation of as little as $10 \%$ of parasite-specific $\mathrm{CD} 4^{+} \mathrm{T}$ cells. Interestingly, Th1 and Th2 cell subsets are endowed with distinct motility programs that regulate their movement in inflamed skin (129). While Th1 cells are dependent on G protein-coupled receptor signaling that facilitate chemokine-driven migration, Th2 cells upregulate integrin $\alpha_{V} \beta_{3}$, allowing them to scan a larger tissue area independent of chemokine gradients (129). These studies indicate that Th1 cells are specifically programmed to sense changes in the environmental milieu during Leishmania infection to maximize effector responses. Despite this, small pools of persistently infected cells remain in the skin (discussed below), arguing that additional mechanisms are in place that prevent complete parasite clearance in vivo, even in the face of strong cellular immunity induction (121).

\section{VISUALIZING IMMUNITY TO CUTANEOUS LEISHMANIASIS IN THE SKIN DURING CHRONIC INFECTION}

\section{Long-Term Persistence of Leishmania Parasites In Vivo}

$\mathrm{BALB} / \mathrm{c}$ mice are known to develop progressive non-healing lesions, but even the resistant C57BL/6 strain takes weeks to heal and a small number of parasites continues to survive in healed skin (38). Persistent Leishmania parasites in the tissue post 
lesion-resolution appear to play a role in the maintenance of memory and protective immunity against reinfection $(48,100)$, but it is not clear whether long-term parasite survival is due to incomplete clearance by $\mathrm{T}$ cells or existence of sanctuary cells that are more hospitable for parasites. Studies from the Beverley lab described two distinct populations of the persistently-infected macrophages in the skin. One subset contained parasites that remain quiescent, whereas parasites in another subset continued to replicate in a manner similar to those during the acute stage of the infection (100). The fact that the number of parasites remain unchanged during the chronic stages of infection strongly suggests that a state of equilibrium between proliferation and immunity has been established. This is consistent with the fact that a complete clearance of parasites results in a total loss of immunity $(50,130)$. These studies also showed that persistent parasites were found within iNOS $^{+}$host cells, which were previously thought to completely clear parasites through NO production (100). This observation argues against the presence of "sanctuary sites" that can accommodate long-term L. major infections in the skin. A possible explanation is that either NO preferentially kills metabolically active parasites, or that persistent parasites are resistant to iNOS-mediated killing (100). Alternatively, continual low influx of susceptible inflammatory monocyte may contribute to host cell reservoir upon infection and maturation (45). These studies highlight possible cell intrinsic and extrinsic mechanisms that promote persistent infection that have the potential to re-established active disease, and questions remain why strong cell-mediated immunity are not able to completely remove infection.

Upon resolution of primary Leishmania infection, patients exhibit a long-lasting, $\mathrm{CD} 4^{+} \mathrm{T}$ cell-dependent concomitant immunity to reinfection, but $10^{2}-10^{4}$ parasites remain detectable at the site of primary infection and in the draining lymph nodes $(48,53,100,131)$. These parasites seem vital in maintaining memory $\mathrm{CD}^{+} \mathrm{T}$ cells that can rapidly respond to subsequent Leishmania challenge. However, unlike generation of long-lived $\mathrm{CD}^{+} \mathrm{T}$ cells during viral infection, maintenance of memory $\mathrm{CD}^{+} \mathrm{T}$ cells against intracellular parasites remains poorly understood. Effector memory $\mathrm{T}$ cells $\left(\mathrm{T}_{\mathrm{EM}}\right)$ are generated during primary infection, yet it is currently not clear whether these cells also require a small pool of parasites for their longterm maintenance $(52,132)$. Central memory $\mathrm{T}$ cells $\left(\mathrm{T}_{\mathrm{CM}}\right)$ home to secondary lymphoid organs, such as the draining lymph node, where they proliferate and differentiate into effector $\mathrm{T}$ cells and migrate back to the lesion sites to mediate effector activities (52). $\mathrm{T}_{\mathrm{CM}}$ are thought to serve as a long-lived source of Leishmania-specific effector $\mathrm{T}$ cells upon re-challenge and have been shown to survive in the absence of parasites (52), although this has not been observed in other studies $(51,130)$. Adoptive transfer of memory $\mathrm{CD} 4^{+} \mathrm{T}$ cell populations into naïve mice leads to their recruitment and enhanced parasite control upon Leishmania challenge $(52,53)$, but do not provide the same level of protection as those in immune animals. One possible explanation is the establishment of $\mathrm{CD} 4^{+} \mathrm{T}_{\mathrm{RM}}$ in skin that facilitate recruitment of circulating memory $\mathrm{T}$ cells (133) and inflammatory monocytes (134) to aid in parasite clearance, the latter through ROS and iNOS production. Rapid influx of shortlived $\mathrm{CD}^{+} \mathrm{Ly}_{6 \mathrm{C}^{+}}$Tbet $^{\text {hi }} \mathrm{T}$ cells that are not derived from reactivated memory $\mathrm{T}$ cell pools have also been described to facilitate parasite clearance upon secondary challenge (53), highlighting the contributions from multiple immune subsets towards anti-Leishmanial immunity. In contrast, regulatory $\mathrm{T}$ cells are present in healed lesions, and can suppress effector $\mathrm{CD} 4{ }^{+} \mathrm{T}$ cell function through IL-10 dependent and independent mechanisms (130). Sterilizing immunity can be achieved upon in vivo depletion of regulatory T cells (130), strongly arguing that Tregs are important in establishing a tolerogenic environment that promote long-term parasite survival. Consistent with this, healed mice challenged with heat-killed Leishmania parasites led to the rapid expansion of IL-10-producing regulatory $\mathrm{T}$ cells resulting in disease (lesion) reactivation (62). These data argue that an equilibrium is established between regulatory and effector $\mathrm{T}$ cells that help maintain a pool of persistently infected macrophages, and that disruption of this balance can reestablish infection $(63,135)$. What remains to be established is the dynamic interplay between regulatory $\mathrm{T}$ cells and effector $\mathrm{CD}^{+} \mathrm{T}$ cells within healed skin that contribute to parasite persistence in vivo, and whether Tregs need to see Leishmania antigen to establish a tolerogenic environment (136). 2PTM studies of healed skin will undoubtedly provide unprecedented insights into physical and cellular barriers that prevent complete parasite clearance and will provide insights into the barriers in place to achieve sterilizing, long-lasting immunity.

\section{CONCLUDING REMARKS}

Parasites have evolved sophisticated mechanisms to evade detection from the immune system and to survive under harsh conditions. Some of the challenges against developing a vaccine against vector-borne infections, such as Leishmania spp., include the complexity in its route of infection, digenetic life cycle and their ability to counteract host immunity to establish a chronic infection. Intravital microscopy of infected mice has allowed for comparative analyses of dynamic host responses at various stages of disease in multiple organ sites. Yet, there is conflicting data on the contribution of immune subsets to protective immunity, as this seems to vary depending on the route of infection and the species used for infection studies. Future studies must compare and contrast immune responses to different parasite species, with an emphasis on why parasites can establish a persistent infection despite generation of a strong Th1 response. Intravital studies will be instrumental in revealing immune players, such as eosinophils or regulatory $\mathrm{T}$ cells, that are responsible for generating and maintaining a permissive environment that promote long-term parasite survival. Visualizing complex behaviors such as neutrophil extravasation from blood and their swarming at the site of bite injury (17), L. major transmission between cells through efferocytosis (104), and dynamic capture of L. major promastigotes by migratory dermal DCs in the skin (90) can only be accomplished by IVM directly in living tissues, and helps illuminate dynamic host: 
parasite interactions in vivo that cannot be captured by conventional, static approaches. Integrating intravital microscopy with other novel approaches, such as spatial transcriptomics analysis, will help reveal how tissue heterogeneity and gene expression impacts cellular behaviors to describe mechanisms in place to ensure parasite survival. These and other complementary approaches may translate into the development of new therapeutics against parasitic infections.

\section{AUTHOR CONTRIBUTIONS}

Conceptualization RZ and TM. Writing - original draft preparation RZ and TM. Writing - review and editing RZ, TM, and JU. Figures RZ. Supervision TM. Funding acquisition

\section{REFERENCES}

1. Mempel TR, Henrickson SE, Von Andrian UH. T-Cell Priming by Dendritic Cells in Lymph Nodes Occurs in Three Distinct Phases. Nature (2004) 427 (6970):154-9. doi: 10.1038/nature02238

2. Stoll S, Delon J, Brotz TM, Germain RN. Dynamic Imaging of T CellDendritic Cell Interactions in Lymph Nodes. Science (2002) 296 (5574):1873-6. doi: 10.1126/science.1071065

3. Miller MJ, Wei SH, Parker I, Cahalan MD. Two-Photon Imaging of Lymphocyte Motility and Antigen Response in Intact Lymph Node. Science (2002) 296(5574):1869-73. doi: 10.1126/science.1070051

4. Bousso P, Bhakta NR, Lewis RS, Robey E. Dynamics of Thymocyte-Stromal Cell Interactions Visualized by Two-Photon Microscopy. Science (2002) 296 (5574):1876-80. doi: 10.1126/science.1070945

5. Allen CD, Okada T, Cyster JG. Germinal-Center Organization and Cellular Dynamics. Immunity (2007) 27(2):190-202. doi: 10.1016/j.immuni.2007.07.009

6. Schwickert TA, Lindquist RL, Shakhar G, Livshits G, Skokos D, KoscoVilbois MH, et al. In Vivo Imaging of Germinal Centres Reveals a Dynamic Open Structure. Nature (2007) 446(7131):83-7. doi: 10.1038/nature05573

7. Melichar HJ, Li O, Herzmark P, Padmanabhan RK, Oliaro J, LudfordMenting MJ, et al. Quantifying Subcellular Distribution of Fluorescent Fusion Proteins in Cells Migrating Within Tissues. Immunol Cell Biol (2011) 89(4):549-57. doi: 10.1038/icb.2010.122

8. Marangoni F, Murooka TT, Manzo T, Kim EY, Carrizosa E, Elpek NM, et al. The Transcription Factor NFAT Exhibits Signal Memory During Serial T Cell Interactions With Antigen-Presenting Cells. Immunity (2013) 38 (2):237-49. doi: 10.1016/j.immuni.2012.09.012

9. Bousso P, Moreau HD. Functional Immunoimaging: The Revolution Continues. Nat Rev Immunol (2012) 12(12):858-64. doi: 10.1038/nri3342

10. Mempel TR, Scimone ML, Mora JR, von Andrian UH. In Vivo Imaging of Leukocyte Trafficking in Blood Vessels and Tissues. Curr Opin Immunol (2004) 16(4):406-17. doi: 10.1016/j.coi.2004.05.018

11. Murooka TT, Mempel TR. Intravital Microscopy in BLT-humanized Mice to Study Cellular Dynamics in HIV Infection. J Infect Dis (2013) 208 Suppl 2: S137-44. doi: 10.1093/infdis/jit447

12. Sewald X. Visualizing Viral Infection In Vivo by Multi-Photon Intravital Microscopy. Viruses (2018) 10(6):337. doi: 10.3390/v10060337

13. Mandl JN, Torabi-Parizi P, Germain RN. Visualization and Dynamic Analysis of Host-Pathogen Interactions. Curr Opin Immunol (2014) 29:815. doi: 10.1016/j.coi.2014.03.002

14. Denk W, Strickler JH, Webb WW. Two-Photon Laser Scanning Fluorescence Microscopy. Science (1990) 248(4951):73-6. doi: 10.1126/ science. 2321027

15. Dawson JB, Barker DJ, Ellis DJ, Grassam E, Cotterill JA, Fisher GW, et al. A Theoretical and Experimental Study of Light Absorption and Scattering by In Vivo Skin. Phys Med Biol (1980) 25(4):695-709. doi: 10.1088/0031-9155/ 25/4/008
JU and TM. All authors contributed to the article and approved the submitted version.

\section{FUNDING}

This work was supported by the CIHR-GSK Partnered Program (TM) and a studentship from Research Manitoba and University of Manitoba Student Fellowship (RZ). JU is supported by a CIHR Project grant MOP 114932.

\section{ACKNOWLEDGMENTS}

All figures were created using Keynote.

16. Konig K. Multiphoton Microscopy in Life Sciences. J Microsc (2000) 200(Pt 2):83-104. doi: 10.1046/j.1365-2818.2000.00738.x

17. Peters NC, Egen JG, Secundino N, Debrabant A, Kimblin N, Kamhawi S, et al. In Vivo Imaging Reveals an Essential Role for Neutrophils in Leishmaniasis Transmitted by Sand Flies. Science (2008) 321(5891):970-4. doi: 10.1126/science.1159194

18. Jain R, Tikoo S, Weninger W. Recent Advances in Microscopic Techniques for Visualizing Leukocytes In Vivo. F1000Res (2016) 5:915. doi: 10.12688/ f1000research.8127.1

19. Alex H, Scherer A, Kreuzburg S, Abers MS, Zerbe CS, Dinauer MC, et al. Neutrophil Swarming Delays the Growth of Clusters of Pathogenic Fungi. Nat Commun (2020) 11(1):2031. doi: 10.1038/s41467-020-15834-4

20. Lammermann T, Afonso PV, Angermann BR, Wang JM, Kastenmuller W, Parent CA, et al. Neutrophil Swarms Require LTB4 and Integrins At Sites of Cell Death In Vivo. Nature (2013) 498(7454):371-5. doi: 10.1038/nature12175

21. Chtanova T, Schaeffer M, Han SJ, van Dooren GG, Nollmann M, Herzmark P, et al. Dynamics of Neutrophil Migration in Lymph Nodes During Infection. Immunity (2008) 29(3):487-96. doi: 10.1016/j.immuni.2008.07.012

22. Surewaard BG, Deniset JF, Zemp FJ, Amrein M, Otto M, Conly J, et al. Identification and Treatment of the Staphylococcus Aureus Reservoir In Vivo. J Exp Med (2016) 213(7):1141-51. doi: 10.1084/jem.20160334

23. Uderhardt S, Martins AJ, Tsang JS, Lammermann T, Germain RN. Resident Macrophages Cloak Tissue Microlesions to Prevent Neutrophil-Driven Inflammatory Damage. Cell (2019) 177(3):541-55 e17. doi: 10.1016/ j.cell.2019.02.028

24. Neupane AS, Willson M, Chojnacki AK, Vargas ESCF, Morehouse C, Carestia A, et al. Patrolling Alveolar Macrophages Conceal Bacteria From the Immune System to Maintain Homeostasis. Cell (2020) 183(1):110-25 e11. doi: 10.1016/j.cell.2020.08.020

25. Ratto-Kim S, Yoon IK, Paris RM, Excler JL, Kim JH, O'Connell RJ. The US Military Commitment to Vaccine Development: A Century of Successes and Challenges. Front Immunol (2018) 9:1397. doi: 10.3389/fimmu.2018.01397

26. Wyse BA, Oshidari R, Jeffery DC, Yankulov KY. Parasite Epigenetics and Immune Evasion: Lessons From Budding Yeast. Epigenet Chromatin (2013) 6(1):40. doi: 10.1186/1756-8935-6-40

27. Renia L, Goh YS. Malaria Parasites: The Great Escape. Front Immunol (2016) 7:463. doi: 10.3389/fimmu.2016.00463

28. World Health O. Control of the Leishmaniases. World Health Organ Tech Rep Ser (2010) 949):xii-xiii, 1-186, back cover.

29. Bretscher PA, Wei G, Menon JN, Bielefeldt-Ohmann H. Establishment of Stable, Cell-Mediated Immunity That Makes "Susceptible" Mice Resistant to Leishmania Major. Science (1992) 257(5069):539-42. doi: 10.1126/ science. 1636090

30. Silva JM, Zacarias DA, de Figueiredo LC, Soares MR, Ishikawa EA, Costa DL, et al. Bone Marrow Parasite Burden Among Patients With New World Kala-Azar is Associated With Disease Severity. Am J Trop Med Hyg (2014) 90(4):621-6. doi: 10.4269/ajtmh.13-0376 
31. Abdeladhim M, Kamhawi S, Valenzuela JG. What's Behind a Sand Fly Bite? The Profound Effect of Sand Fly Saliva on Host Hemostasis, Inflammation and Immunity. Infect Genet Evol (2014) 28:691-703. doi: 10.1016/ j.meegid.2014.07.028

32. Ribeiro-Gomes FL, Roma EH, Carneiro MB, Doria NA, Sacks DL, Peters NC. Site-Dependent Recruitment of Inflammatory Cells Determines the Effective Dose of Leishmania Major. Infect Immun (2014) 82(7):2713-27. doi: 10.1128/IAI.01600-13

33. Naik S, Bouladoux N, Wilhelm C, Molloy MJ, Salcedo R, Kastenmuller W, et al. Compartmentalized Control of Skin Immunity by Resident Commensals. Science (2012) 337(6098):1115-9. doi: 10.1126/science.1225152

34. Gimblet C, Meisel JS, Loesche MA, Cole SD, Horwinski J, Novais FO, et al. Cutaneous Leishmaniasis Induces a Transmissible Dysbiotic Skin Microbiota That Promotes Skin Inflammation. Cell Host Microbe (2017) 22(1):13-24 e4. doi: 10.1016/j.chom.2017.06.006

35. Kelly PH, Bahr SM, Serafim TD, Ajami NJ, Petrosino JF, Meneses C, et al. The Gut Microbiome of the Vector Lutzomyia Longipalpis Is Essential for Survival of Leishmania Infantum. MBio (2017) 8(1):e01121-16. doi: 10.1128/mBio.01121-16

36. Dey R, Joshi AB, Oliveira F, Pereira L, Guimaraes-Costa AB, Serafim TD, et al. Gut Microbes Egested During Bites of Infected Sand Flies Augment Severity of Leishmaniasis Via Inflammasome-Derived IL-1beta. Cell Host Microbe (2018) 23(1):134-43 e6. doi: 10.1016/j.chom.2017.12.002

37. Louradour I, Monteiro CC, Inbar E, Ghosh K, Merkhofer R, Lawyer P, et al. The Midgut Microbiota Plays an Essential Role in Sand Fly Vector Competence for Leishmania Major. Cell Microbiol (2017) 19(10). doi: 10.1111/cmi.12755

38. Scott P, Novais FO. Cutaneous Leishmaniasis: Immune Responses in Protection and Pathogenesis. Nat Rev Immunol (2016) 16(9):581-92. doi: $10.1038 /$ nri.2016.72

39. Scott P, Natovitz P, Coffman RL, Pearce E, Sher A. Immunoregulation of Cutaneous Leishmaniasis. T Cell Lines That Transfer Protective Immunity or Exacerbation Belong to Different T Helper Subsets and Respond to Distinct Parasite Antigens. J Exp Med (1988) 168(5):1675-84. doi: 10.1084/ jem.168.5.1675

40. Green SJ, Crawford RM, Hockmeyer JT, Meltzer MS, Nacy CA. Leishmania Major Amastigotes Initiate the L-arginine-dependent Killing Mechanism in IFN-gamma-stimulated Macrophages by Induction of Tumor Necrosis Factor-Alpha. J Immunol (1990) 145(12):4290-7.

41. Liew FY, Millott S, Parkinson C, Palmer RM, Moncada S. Macrophage Killing of Leishmania Parasite In Vivo is Mediated by Nitric Oxide From LArginine. J Immunol (1990) 144(12):4794-7.

42. Liew FY, Li Y, Millott S. Tumor Necrosis Factor-Alpha Synergizes With IFN-gamma in Mediating Killing of Leishmania Major Through the Induction of Nitric Oxide. J Immunol (1990) 145(12):4306-10.

43. Romano A, Carneiro MBH, Doria NA, Roma EH, Ribeiro-Gomes FL, Inbar E, et al. Divergent Roles for Ly6C+CCR2+CX3CR1+ Inflammatory Monocytes During Primary or Secondary Infection of the Skin With the Intra-Phagosomal Pathogen Leishmania Major. PLoS Pathog (2017) 13(6): e1006479. doi: 10.1371/journal.ppat.1006479

44. Leon B, Lopez-Bravo M, Ardavin C. Monocyte-Derived Dendritic Cells Formed At the Infection Site Control the Induction of Protective T Helper 1 Responses Against Leishmania. Immunity (2007) 26(4):519-31. doi: 10.1016/j.immuni.2007.01.017

45. Carneiro MB, Lopes ME, Hohman LS, Romano A, David BA, Kratofil R, et al. Th1-Th2 Cross-Regulation Controls Early Leishmania Infection in the Skin by Modulating the Size of the Permissive Monocytic Host Cell Reservoir. Cell Host Microbe (2020) 27(5):752-68 e7. doi: 10.1016/j.chom.2020.03.011

46. Gantt KR, Goldman TL, McCormick ML, Miller MA, Jeronimo SM, Nascimento ET, et al. Oxidative Responses of Human and Murine Macrophages During Phagocytosis of Leishmania Chagasi. J Immunol (2001) 167(2):893-901. doi: 10.4049/jimmunol.167.2.893

47. Bacellar O, Lessa H, Schriefer A, Machado P, Ribeiro de Jesus A, Dutra WO, et al. Up-Regulation of Th1-Type Responses in Mucosal Leishmaniasis Patients. Infect Immun (2002) 70(12):6734-40. doi: 10.1128/iai.70.12.67346740.2002

48. Okwor I, Mou Z, Liu D, Uzonna J. Protective Immunity and Vaccination Against Cutaneous Leishmaniasis. Front Immunol (2012) 3:128. doi: $10.3389 /$ fimmu.2012.00128
49. Pace D. Leishmaniasis. J Infect (2014) 69(Suppl 1):S10-8. doi: 10.1016/ j.jinf.2014.07.016

50. Uzonna JE, Wei G, Yurkowski D, Bretscher P. Immune Elimination of Leishmania Major in Mice: Implications for Immune Memory, Vaccination, and Reactivation Disease. J Immunol (2001) 167(12):6967-74. doi: 10.4049/ jimmunol.167.12.6967

51. Belkaid Y, Hoffmann KF, Mendez S, Kamhawi S, Udey MC, Wynn TA, et al. The Role of Interleukin (IL)-10 in the Persistence of Leishmania Major in the Skin After Healing and the Therapeutic Potential of anti-IL-10 Receptor Antibody for Sterile Cure. J Exp Med (2001) 194(10):1497-506. doi: 10.1084/ jem.194.10.1497

52. Zaph C, Uzonna J, Beverley SM, Scott P. Central Memory T Cells Mediate Long-Term Immunity to Leishmania Major in the Absence of Persistent Parasites. Nat Med (2004) 10(10):1104-10. doi: 10.1038/nm1108

53. Peters NC, Pagan AJ, Lawyer PG, Hand TW, Henrique Roma E, Stamper LW, et al. Chronic Parasitic Infection Maintains High Frequencies of ShortLived Ly6C+CD4+ Effector T Cells That are Required for Protection Against Re-Infection. PLoS Pathog (2014) 10(12):e1004538. doi: 10.1371/ journal.ppat.1004538

54. Morgado FN, Schubach A, Vasconcellos E, Azeredo-Coutinho RB, ValeteRosalino CM, Quintella LP, et al. Signs of an in Situ Inflammatory Reaction in Scars of Human American Tegumentary Leishmaniasis. Parasit Immunol (2010) 32(4):285-95. doi: 10.1111/j.1365-3024.2009.01188.x

55. Romero I, Tellez J, Suarez Y, Cardona M, Figueroa R, Zelazny A, et al. Viability and Burden of Leishmania in Extralesional Sites During Human Dermal Leishmaniasis. PLoS Negl Trop Dis (2010) 4(9):e819. doi: 10.1371/ journal.pntd.0000819

56. Canario A, Queiroz M, Cunha G, Cavalcante T, Riesz V, Sharma R, et al. Presence of Parasite DNA in Clinically Unaffected Nasal Mucosa During Cutaneous Leishmaniasis Caused by Leishmania (Viannia) Braziliensis. Clin Microbiol Infect (2019) 25(4):515 e5- e7. doi: 10.1016/j.cmi.2018.12.027

57. Singh RP, Picado A, Alam S, Hasker E, Singh SP, Ostyn B, et al. Post-KalaAzar Dermal Leishmaniasis (PKDL) in Visceral Leishmaniasis-Endemic Communities in Bihar, India. Trop Med Int Health (2012) 17(11):1345-8. doi: $10.1111 /$ tmi.12044

58. Ganguly S, Das NK, Barbhuiya JN, Chatterjee M. Post-Kala-Azar Dermal Leishmaniasis-an Overview. Int J Dermatol (2010) 49(8):921-31. doi: $10.1111 / j .1365-4632.2010 .04558 . x$

59. Conceicao-Silva F, Leite-Silva J, Morgado FN. The Binomial Parasite-Host Immunity in the Healing Process and in Reactivation of Human Tegumentary Leishmaniasis. Front Microbiol (2018) 9:1308. doi: 10.3389/fmicb.2018.01308

60. Ceccarelli M, Rullo EV, Condorelli F, Vitale F, Marco VD, Nunnari G, et al. Unusual Signs and Symptoms in HIV-Positive Patients Coinfected With Leishmania Spp: The Importance of Neglected Tropical Disease in Differential Diagnosis. Open Access Maced J Med Sci (2018) 6(5):843-7. doi: 10.3889/oamjms.2018.186

61. Lonardoni MVC, Oliveira ÉA, Celidônio FA, Silveira TGV. Evaluation of HIV-Leishmania Co-Infection in Patients From the Northwestern Paraná State, Brazil. Acta Sci Health Sci (2011) 33(1). doi: 10.4025/actascihealthsci. v33i1.6976

62. Okwor I, Liu D, Beverley SM, Uzonna JE. Inoculation of Killed Leishmania Major Into Immune Mice Rapidly Disrupts Immunity to a Secondary Challenge Via IL-10-mediated Process. Proc Natl Acad Sci USA (2009) 106(33):13951-6. doi: 10.1073/pnas.0905184106

63. Mendez S, Reckling SK, Piccirillo CA, Sacks D, Belkaid Y. Role for CD4(+) CD25(+) Regulatory T Cells in Reactivation of Persistent Leishmaniasis and Control of Concomitant Immunity. J Exp Med (2004) 200(2):201-10. doi: 10.1084/jem.20040298

64. Tabbara KS, Peters NC, Afrin F, Mendez S, Bertholet S, Belkaid Y, et al. Conditions Influencing the Efficacy of Vaccination With Live Organisms Against Leishmania Major Infection. Infect Immun (2005) 73(8):4714-22. doi: 10.1128/IAI.73.8.4714-4722.2005

65. Dostalova A, Volf P. Leishmania Development in Sand Flies: Parasite-Vector Interactions Overview. Parasit Vectors (2012) 5:276. doi: 10.1186/17563305-5-276

66. Giraud E, Martin O, Yakob L, Rogers M. Quantifying Leishmania Metacyclic Promastigotes From Individual Sandfly Bites Reveals the Efficiency of Vector Transmission. Commun Biol (2019) 2:84. doi: 10.1038/s42003-019-0323-8 
67. Rogers ME, Ilg T, Nikolaev AV, Ferguson MA, Bates PA. Transmission of Cutaneous Leishmaniasis by Sand Flies is Enhanced by Regurgitation of Fppg. Nature (2004) 430(6998):463-7. doi: 10.1038/nature02675

68. Dasari S, Weber P, Makhloufi C, Lopez E, Forestier CL. Intravital Microscopy Imaging of the Liver Following Leishmania Infection: An Assessment of Hepatic Hemodynamics. J Vis Exp (2015) 101):e52303. doi: $10.3791 / 52303$

69. Ritsma L, Steller EJ, Ellenbroek SI, Kranenburg O, Borel Rinkes IH, van Rheenen J. Surgical Implantation of an Abdominal Imaging Window for Intravital Microscopy. Nat Protoc (2013) 8(3):583-94. doi: 10.1038/nprot.2013.026

70. Beattie L, Peltan A, Maroof A, Kirby A, Brown N, Coles M, et al. Dynamic Imaging of Experimental Leishmania Donovani-Induced Hepatic Granulomas Detects Kupffer Cell-Restricted Antigen Presentation to Antigen-Specific CD8 T Cells. PLoS Pathog (2010) 6(3):e1000805. doi: 10.1371/journal.ppat.1000805

71. Beattie L, d'El-Rei Hermida M, Moore JW, Maroof A, Brown N, Lagos D, et al. A Transcriptomic Network Identified in Uninfected Macrophages Responding to Inflammation Controls Intracellular Pathogen Survival. Cell Host Microbe (2013) 14(3):357-68. doi: 10.1016/j.chom.2013.08.004

72. Ikeogu NM, Akaluka GN, Edechi CA, Salako ES, Onyilagha C, Barazandeh AF, et al. Leishmania Immunity: Advancing Immunotherapy and Vaccine Development. Microorganisms (2020) 8(8):1201. doi: 10.3390/ microorganisms 8081201

73. Deak E, Jayakumar A, Cho KW, Goldsmith-Pestana K, Dondji B, Lambris JD, et al. Murine Visceral Leishmaniasis: IgM and Polyclonal B-cell Activation Lead to Disease Exacerbation. Eur J Immunol (2010) 40 (5):1355-68. doi: 10.1002/eji.200939455

74. Moore JW, Beattie L, Dalton JE, Owens BM, Maroof A, Coles MC, et al. B Cell: T Cell Interactions Occur Within Hepatic Granulomas During Experimental Visceral Leishmaniasis. PLoS One (2012) 7(3):e34143. doi: 10.1371/journal.pone.0034143

75. Silva-Barrios S, Smans M, Duerr CU, Qureshi ST, Fritz JH, Descoteaux A, et al. Innate Immune B Cell Activation by Leishmania Donovani Exacerbates Disease and Mediates Hypergammaglobulinemia. Cell Rep (2016) 15 (11):2427-37. doi: 10.1016/j.celrep.2016.05.028

76. Mitchell GF, Handman E. Leishmania Tropica Major in Mice: Vaccination Against Cutaneous Leishmaniasis in Mice of High Genetic Susceptibility. Aust J Exp Biol Med Sci (1983) 61(Pt 1):11-25. doi: 10.1038/icb.1983.2

77. Howard JG, Hale C, Liew FY. Immunological Regulation of Experimental Cutaneous Leishmaniasis. IV. Prophylactic Effect of Sublethal Irradiation as a Result of Abrogation of Suppressor T Cell Generation in Mice Genetically Susceptible to Leishmania Tropica. J Exp Med (1981) 153(3):557-68. doi: 10.1084/jem.153.3.557

78. Woelbing F, Kostka SL, Moelle K, Belkaid Y, Sunderkoetter C, Verbeek S, et al. Uptake of Leishmania Major by Dendritic Cells is Mediated by Fcgamma Receptors and Facilitates Acquisition of Protective Immunity. J Exp Med (2006) 203(1):177-88. doi: 10.1084/jem.20052288

79. Melo GD, Goyard S, Fiette L, Boissonnas A, Combadiere C, Machado GF, et al. Unveiling Cerebral Leishmaniasis: Parasites and Brain Inflammation in Leishmania Donovani Infected Mice. Sci Rep (2017) 7(1):8454. doi: 10.1038/ s41598-017-09085-5

80. Carneiro MB, Hohman LS, Egen JG, Peters NC. Use of Two-Photon Microscopy to Study Leishmania Major Infection of the Skin. Methods (2017) 127:45-52. doi: 10.1016/j.ymeth.2017.04.012

81. Ronet C, Passelli K, Charmoy M, Scarpellino L, Myburgh E, Hauyon La Torre Y, et al. Tlr2 Signaling in Skin Nonhematopoietic Cells Induces Early Neutrophil Recruitment in Response to Leishmania Major Infection. J Invest Dermatol (2019) 139(6):1318-28. doi: 10.1016/j.jid.2018.12.012

82. Salei N, Hellberg L, Kohl J, Laskay T. Enhanced Survival of Leishmania Major in Neutrophil Granulocytes in the Presence of Apoptotic Cells. PLoS One (2017) 12(2):e0171850. doi: 10.1371/journal.pone.0171850

83. Hurrell BP, Regli IB, Tacchini-Cottier F. Different Leishmania Species Drive Distinct Neutrophil Functions. Trends Parasit (2016) 32(5):392-401. doi: 10.1016/j.pt.2016.02.003

84. Sousa LM, Carneiro MB, Resende ME, Martins LS, Dos Santos LM, Vaz LG, et al. Neutrophils Have a Protective Role During Early Stages of Leishmania Amazonensis Infection in BALB/c Mice. Parasit Immunol (2014) 36(1):1331. doi: $10.1111 / \mathrm{pim} .12078$
85. Xin L, Vargas-Inchaustegui DA, Raimer SS, Kelly BC, Hu J, Zhu L, et al. Type I IFN Receptor Regulates Neutrophil Functions and Innate Immunity to Leishmania Parasites. J Immunol (2010) 184(12):7047-56. doi: 10.4049/ jimmunol.0903273

86. Novais FO, Santiago RC, Bafica A, Khouri R, Afonso L, Borges VM, et al. Neutrophils and Macrophages Cooperate in Host Resistance Against Leishmania Braziliensis Infection. J Immunol (2009) 183(12):8088-98. doi: 10.4049/jimmunol.0803720

87. Carlsen ED, Jie Z, Liang Y, Henard CA, Hay C, Sun J, et al. Interactions Between Neutrophils and Leishmania Braziliensis Amastigotes Facilitate Cell Activation and Parasite Clearance. J Innate Immun (2015) 7(4):354-63. doi: $10.1159 / 000373923$

88. Charmoy M, Brunner-Agten S, Aebischer D, Auderset F, Launois P, Milon G, et al. Neutrophil-Derived CCL3 is Essential for the Rapid Recruitment of Dendritic Cells to the Site of Leishmania Major Inoculation in Resistant Mice. PLoS Pathog (2010) 6(2):e1000755. doi: 10.1371/journal.ppat.1000755

89. Ribeiro-Gomes FL, Peters NC, Debrabant A, Sacks DL. Efficient Capture of Infected Neutrophils by Dendritic Cells in the Skin Inhibits the Early AntiLeishmania Response. PLoS Pathog (2012) 8(2):e1002536. doi: 10.1371/ journal.ppat.1002536

90. Ng LG, Hsu A, Mandell MA, Roediger B, Hoeller C, Mrass P, et al. Migratory Dermal Dendritic Cells Act as Rapid Sensors of Protozoan Parasites. PLoS Pathog (2008) 4(11):e1000222. doi: 10.1371/journal.ppat.1000222

91. De Trez C, Magez S, Akira S, Ryffel B, Carlier Y, Muraille E. iNOS-producing Inflammatory Dendritic Cells Constitute the Major Infected Cell Type During the Chronic Leishmania Major Infection Phase of C57BL/6 Resistant Mice. PLoS Pathog (2009) 5(6):e1000494. doi: 10.1371/ journal.ppat.1000494

92. Hurrell BP, Schuster S, Grun E, Coutaz M, Williams RA, Held W, et al. Rapid Sequestration of Leishmania Mexicana by Neutrophils Contributes to the Development of Chronic Lesion. PLoS Pathog (2015) 11(5):e1004929. doi: 10.1371/journal.ppat.1004929

93. Hsu AC, Scott P. Leishmania Mexicana Infection Induces Impaired Lymph Node Expansion and Th1 Cell Differentiation Despite Normal T Cell Proliferation. J Immunol (2007) 179(12):8200-7. doi: 10.4049/ jimmunol.179.12.8200

94. Petritus PM, Manzoni-de-Almeida D, Gimblet C, Gonzalez Lombana C, Scott P. Leishmania Mexicana Induces Limited Recruitment and Activation of Monocytes and Monocyte-Derived Dendritic Cells Early During Infection. PLoS Negl Trop Dis (2012) 6(10):e1858. doi: 10.1371/ journal.pntd.0001858

95. Weinheber N, Wolfram M, Harbecke D, Aebischer T. Phagocytosis of Leishmania Mexicana Amastigotes by Macrophages Leads to a Sustained Suppression of IL-12 Production. Eur J Immunol (1998) 28(8):2467-77. doi: 10.1002/(SICI)1521-4141 (199808)28:08<2467::AID-IMMU2467>3.0.CO;2-1

96. Rodriguez-Sosa M, Monteforte GM, Satoskar AR. Susceptibility to Leishmania Mexicana Infection is Due to the Inability to Produce IL-12 Rather Than Lack of IL-12 Responsiveness. Immunol Cell Biol (2001) 79 (4):320-2. doi: 10.1046/j.1440-1711.2001.01014.x

97. Shweash M, Adrienne McGachy H, Schroeder J, Neamatallah T, Bryant CE, Millington $\mathrm{O}$, et al. Leishmania Mexicana Promastigotes Inhibit Macrophage IL-12 Production Via TLR-4 Dependent COX-2, iNOS and Arginase-1 Expression. Mol Immunol (2011) 48(15-16):1800-8. doi: 10.1016/j.molimm.2011.05.013

98. Contreras I, Estrada JA, Guak H, Martel C, Borjian A, Ralph B, et al. Impact of Leishmania Mexicana Infection on Dendritic Cell Signaling and Functions. PLoS Negl Trop Dis (2014) 8(9):e3202. doi: 10.1371/ journal.pntd.0003202

99. Muller AJ, Aeschlimann S, Olekhnovitch R, Dacher M, Spath GF, Bousso P. Photoconvertible Pathogen Labeling Reveals Nitric Oxide Control of Leishmania Major Infection In Vivo Via Dampening of Parasite Metabolism. Cell Host Microbe (2013) 14(4):460-7. doi: 10.1016/ j.chom.2013.09.008

100. Mandell MA, Beverley SM. Continual Renewal and Replication of Persistent Leishmania Major Parasites in Concomitantly Immune Hosts. Proc Natl Acad Sci USA (2017) 114(5):E801-E10. doi: 10.1073/pnas.1619265114

101. Kloehn J, Saunders EC, O’Callaghan S, Dagley MJ, McConville MJ. Characterization of Metabolically Quiescent Leishmania Parasites in 
Murine Lesions Using Heavy Water Labeling. PLoS Pathog (2015) 11(2): e1004683. doi: 10.1371/journal.ppat.1004683

102. Heyde S, Philipsen L, Formaglio P, Fu Y, Baars I, Hobbel G, et al. CD11cExpressing Ly6C+CCR2+ Monocytes Constitute a Reservoir for Efficient Leishmania Proliferation and Cell-to-Cell Transmission. PLoS Pathog (2018) 14(10):e1007374. doi: 10.1371/journal.ppat.1007374

103. Habuchi S, Tsutsui H, Kochaniak AB, Miyawaki A, van Oijen AM. mKikGR, a Monomeric Photoswitchable Fluorescent Protein. PLoS One (2008) 3(12): e3944. doi: 10.1371/journal.pone.0003944

104. Chaves MM, Lee SH, Kamenyeva O, Ghosh K, Peters NC, Sacks D. The Role of Dermis Resident Macrophages and Their Interaction With Neutrophils in the Early Establishment of Leishmania Major Infection Transmitted by Sand Fly Bite. PLoS Pathog (2020) 16(11):e1008674. doi: 10.1371/journal.ppat.1008674

105. Filardy AA, Costa-da-Silva AC, Koeller CM, Guimaraes-Pinto K, RibeiroGomes FL, Lopes MF, et al. Infection With Leishmania Major Induces a Cellular Stress Response in Macrophages. PLoS One (2014) 9(1):e85715. doi: 10.1371/journal.pone.0085715

106. Lievin-Le Moal V, Loiseau PM. Leishmania Hijacking of the Macrophage Intracellular Compartments. FEBS J (2016) 283(4):598-607. doi: 10.1111/ febs. 13601

107. Seguin O, Descoteaux A. Leishmania, the Phagosome, and Host Responses: The Journey of a Parasite. Cell Immunol (2016) 309:1-6. doi: 10.1016/ j.cellimm.2016.08.004

108. Liu D, Uzonna JE. The Early Interaction of Leishmania With Macrophages and Dendritic Cells and its Influence on the Host Immune Response. Front Cell Infect Microbiol (2012) 2:83. doi: 10.3389/fcimb.2012.00083

109. Matte C, Descoteaux A. Exploitation of the Host Cell Membrane Fusion Machinery by Leishmania is Part of the Infection Process. PLoS Pathog (2016) 12(12):e1005962. doi: 10.1371/journal.ppat.1005962

110. Forget G, Gregory DJ, Whitcombe LA, Olivier M. Role of Host Protein Tyrosine Phosphatase SHP-1 in Leishmania Donovani-Induced Inhibition of Nitric Oxide Production. Infect Immun (2006) 74(11):6272-9. doi: 10.1128/IAI.00853-05

111. Abu-Dayyeh I, Shio MT, Sato S, Akira S, Cousineau B, Olivier M. Leishmania-Induced IRAK-1 Inactivation is Mediated by SHP-1 Interacting With an Evolutionarily Conserved KTIM Motif. PLoS Negl Trop Dis (2008) 2(12):e305. doi: 10.1371/journal.pntd.0000305

112. Cameron P, McGachy A, Anderson M, Paul A, Coombs GH, Mottram JC, et al. Inhibition of Lipopolysaccharide-Induced Macrophage IL-12 Production by Leishmania Mexicana Amastigotes: The Role of Cysteine Peptidases and the NF-kappaB Signaling Pathway. J Immunol (2004) 173 (5):3297-304. doi: 10.4049/jimmunol.173.5.3297

113. Arango Duque G, Fukuda M, Turco SJ, Stager S, Descoteaux A. Leishmania Promastigotes Induce Cytokine Secretion in Macrophages Through the Degradation of Synaptotagmin XI. J Immunol (2014) 193(5):2363-72. doi: 10.4049/jimmunol.1303043

114. Anderson CF, Mendez S, Sacks DL. Nonhealing Infection Despite Th1 Polarization Produced by a Strain of Leishmania Major in C57BL/6 Mice. J Immunol (2005) 174(5):2934-41. doi: 10.4049/jimmunol.174.5.2934

115. Lee SH, Charmoy M, Romano A, Paun A, Chaves MM, Cope FO, et al. Mannose Receptor High, M2 Dermal Macrophages Mediate Nonhealing Leishmania Major Infection in a Th1 Immune Environment. J Exp Med (2018) 215(1):357-75. doi: 10.1084/jem.20171389

116. Lee SH, Chaves MM, Kamenyeva O, Gazzinelli-Guimaraes PH, Kang B, Pessenda G, et al. M2-Like, Dermal Macrophages are Maintained Via IL-4/CCL24-mediated Cooperative Interaction With Eosinophils in Cutaneous Leishmaniasis. Sci Immunol (2020) 5(46):eaaz4415. doi: 10.1126/sciimmunol.aaz4415

117. Weiss G, Schaible UE. Macrophage Defense Mechanisms Against Intracellular Bacteria. Immunol Rev (2015) 264(1):182-203. doi: 10.1111/ imr.12266

118. Chatzigeorgiou A, Lyberi M, Chatzilymperis G, Nezos A, Kamper E. CD40/ CD40L Signaling and its Implication in Health and Disease. Biofactors (2009) 35(6):474-83. doi: 10.1002/biof.62

119. Chakraborty D, Banerjee S, Sen A, Banerjee KK, Das P, Roy S. Leishmania Donovani Affects Antigen Presentation of Macrophage by Disrupting Lipid Rafts. J Immunol (2005) 175(5):3214-24. doi: 10.4049/jimmunol.175.5.3214

120. Meier CL, Svensson M, Kaye PM. Leishmania-Induced Inhibition of Macrophage Antigen Presentation Analyzed At the Single-Cell Level. J Immunol (2003) 171(12):6706-13. doi: 10.4049/jimmunol.171.12.6706
121. Prina E, Lang T, Glaichenhaus N, Antoine JC. Presentation of the Protective Parasite Antigen LACK by Leishmania-infected Macrophages. J Immunol (1996) 156(11):4318-27.

122. Fruth U, Solioz N, Louis JA. Leishmania Major Interferes With Antigen Presentation by Infected Macrophages. J Immunol (1993) 150(5):1857-64.

123. Matheoud D, Moradin N, Bellemare-Pelletier A, Shio MT, Hong WJ, Olivier $\mathrm{M}$, et al. Leishmania Evades Host Immunity by Inhibiting Antigen CrossPresentation Through Direct Cleavage of the SNARE Vamp8. Cell Host Microbe (2013) 14(1):15-25. doi: 10.1016/j.chom.2013.06.003

124. Kima PE, Soong L, Chicharro C, Ruddle NH, McMahon-Pratt D. Leishmania-Infected Macrophages Sequester Endogenously Synthesized Parasite Antigens From Presentation to CD4+ T Cells. Eur J Immunol (1996) 26(12):3163-9. doi: 10.1002/eji.1830261249

125. Kelly BL, Stetson DB, Locksley RM. Leishmania Major LACK Antigen is Required for Efficient Vertebrate Parasitization. J Exp Med (2003) 198 (11):1689-98. doi: 10.1084/jem.20031162

126. Filipe-Santos O, Pescher P, Breart B, Lippuner C, Aebischer T, Glaichenhaus $\mathrm{N}$, et al. A Dynamic Map of Antigen Recognition by CD4 T Cells At the Site of Leishmania Major Infection. Cell Host Microbe (2009) 6(1):23-33. doi: 10.1016/j.chom.2009.04.014

127. Aseffa A, Gumy A, Launois P, MacDonald HR, Louis JA, Tacchini-Cottier F. The Early Il-4 Response to Leishmania Major and the Resulting Th2 Cell Maturation Steering Progressive Disease in BALB/c Mice Are Subject to the Control of Regulatory Cd4+Cd25+ T Cells. J Immunol (2002) 169(6):323241. doi: $10.4049 /$ jimmunol.169.6.3232

128. Muller AJ, Filipe-Santos O, Eberl G, Aebischer T, Spath GF, Bousso P. Cd4+ T Cells Rely on a Cytokine Gradient to Control Intracellular Pathogens Beyond Sites of Antigen Presentation. Immunity (2012) 37(1):147-57. doi: 10.1016/j.immuni.2012.05.015

129. Gaylo-Moynihan A, Prizant H, Popovic M, Fernandes NRJ, Anderson CS, Chiou KK, et al. Programming of Distinct Chemokine-Dependent and -Independent Search Strategies for Th1 and Th2 Cells Optimizes Function At Inflamed Sites. Immunity (2019) 51(2):298-309 e6. doi: 10.1016/ j.immuni.2019.06.026

130. Belkaid Y, Piccirillo CA, Mendez S, Shevach EM, Sacks DL. CD4+CD25+ Regulatory T Cells Control Leishmania Major Persistence and Immunity. Nature (2002) 420(6915):502-7. doi: 10.1038/nature01152

131. Romano A, Doria NA, Mendez J, Sacks DL, Peters NC. Cutaneous Infection With Leishmania Major Mediates Heterologous Protection Against Visceral Infection With Leishmania Infantum. J Immunol (2015) 195(8):3816-27. doi: 10.4049/jimmunol.1500752

132. Colpitts SL, Dalton NM, Scott P. IL-7 Receptor Expression Provides the Potential for Long-Term Survival of Both CD62Lhigh Central Memory T Cells and Th1 Effector Cells During Leishmania Major Infection. J Immunol (2009) 182(9):5702-11. doi: 10.4049/jimmunol.0803450

133. Glennie ND, Yeramilli VA, Beiting DP, Volk SW, Weaver CT, Scott P. SkinResident Memory CD4+ T Cells Enhance Protection Against Leishmania Major Infection. J Exp Med (2015) 212(9):1405-14. doi: 10.1084/ jem.20142101

134. Glennie ND, Volk SW, Scott P. Skin-Resident CD4+ T Cells Protect Against Leishmania Major by Recruiting and Activating Inflammatory Monocytes. PLoS Pathog (2017) 13(4):e1006349. doi: 10.1371/journal.ppat.1006349

135. Belkaid Y, Sun CM, Bouladoux N. Parasites and Immunoregulatory T Cells. Curr Opin Immunol (2006) 18(4):406-12. doi: 10.1016/j.coi.2006.05.014

136. Abdel-Gadir A, Massoud AH, Chatila TA. Antigen-Specific Treg Cells in Immunological Tolerance: Implications for Allergic Diseases. F1000Res (2018) 7:38. doi: 10.12688/f1000research.12650.1

Conflict of Interest: The authors declare that the research was conducted in the absence of any commercial or financial relationships that could be construed as a potential conflict of interest.

Copyright (C) 2021 Zayats, Uzonna and Murooka. This is an open-access article distributed under the terms of the Creative Commons Attribution License (CC BY). The use, distribution or reproduction in other forums is permitted, provided the original author(s) and the copyright owner(s) are credited and that the original publication in this journal is cited, in accordance with accepted academic practice. No use, distribution or reproduction is permitted which does not comply with these terms. 